\title{
Summary of the British Thoracic Society Guidelines for advanced diagnostic and therapeutic flexible bronchoscopy in adults
}

\author{
I A Du Rand, ${ }^{1}$ P V Barber, ${ }^{2}$ J Goldring, ${ }^{3}$ R A Lewis, ${ }^{4}$ S Mandal, ${ }^{5}$ M Munavvar, ${ }^{6}$ \\ R C Rintoul, ${ }^{7} \mathrm{P}$ L Shah, ${ }^{8}$ S Singh, ${ }^{9}$ M G Slade, ${ }^{7}$ A Woolley, ${ }^{4}$ BTS Interventional \\ Bronchoscopy Guideline Group
}

${ }^{1}$ Queen Elizabeth Hospital, Birmingham, UK

${ }^{2}$ NorthWest Lung Centre, University Hospital of South Manchester, UK

${ }^{3}$ Royal Free Hospital, London, UK

${ }^{4}$ Worcester Royal Hospital, Worcester, UK

5 Lane Fox Unit, St Thomas' Hospital, London, UK

${ }^{6}$ Lancashire Teaching Hospitals NHS Trust, Preston, UK ${ }^{7}$ Department of Thoracic Oncology, Papworth Hospital, Cambridge, UK

${ }^{8}$ Department of Respiratory Medicine at Royal Brompton Hospital, London, Chelsea and Westminster Hospital, and Imperial College, London, UK ${ }^{9}$ Chelsea and Westminster Hospital, London, UK

\section{Correspondence to}

Dr Ingrid A Du Rand, The British Thoracic Society, 17 Doughty Street, London WC1N 2PL, UK; ingrid.durand@nhs.net

Received 5 September 2011 Accepted 6 September 2011

\begin{abstract}
This new guideline covers the rapidly advancing field of interventional bronchoscopy using flexible bronchoscopy. It includes the use of more complex diagnostic procedures such as endobronchial ultrasound, interventions for the relief of central airway obstruction due to malignancy and the recent development of endobronchial therapies for chronic obstructive pulmonary disease and asthma. The guideline aims to help all those who undertake flexible bronchoscopy to understand more about this important area. It also aims to inform respiratory physicians and other specialists dealing with lung cancer of the procedures possible in the management and palliation of central airway obstruction. The guideline covers transbronchial needle aspiration and endobronchial ultrasound-guided transbronchial needle aspiration, electrocautery/diathermy, argon plasma coagulation and thermal laser, cryotherapy, cryoextraction, photodynamic therapy, brachytherapy, tracheobronchial stenting, electromagnetic navigation bronchoscopy, endobronchial valves for emphysema and bronchial thermoplasty for asthma.
\end{abstract}

This guideline is based on the best available evidence. The methodology used to write the guideline adheres strictly to the criteria as set by the Appraisal of Guidelines Research and Evaluation (AGREE) collaboration http://www.agreecollaboration.org/1/agreeguide/. Three hundred and eighty-seven papers were critically appraised using the Scottish Intercollegiate Guidelines Network (SIGN) critical appraisal checklists. A web-based guideline development tool (http://www. bronchoscopy-guideline.org/) enabled each pair of reviewers to collaborate online. The reliability of the evidence in each individual study was graded using the SIGN critical appraisal checklist. The body of evidence for each recommendation was summarised into evidence tables, formulated into evidence statements and graded using the SIGN grading system into recommendations.

\section{DIAGNOSTIC TECHNIQUES}

Conventional transbronchial needle aspiration

Conventional transbronchial needle aspiration (TBNA) is a safe and simple procedure mainly used to sample hilar and mediastinal lymph nodes in cases of suspected malignant involvement or sarcoidosis (Evidence level $2++$ ). It should be used at the time of initial bronchoscopy to sample lymphadenopathy noted on CT scanning. The guideline includes a step-by-step guide for performing conventional TBNA.

\section{Endobronchial ultrasound-guided transbronchial needle aspiration}

Endobronchial ultrasound transbronchial needle aspiration (EBUS TBNA) has high sensitivity and specificity for identifying malignancy in mediastinal and hilar lymph nodes in patients with lung cancer (Evidence level $2++$ ), and also has a high sensitivity for identifying malignancy when used for sampling paratracheal and peribronchial parenchymal lung masses (Evidence level 3 ). In cases where EBUS-TBNA results are negative for malignancy, a confirmatory surgical biopsy should be performed. EBUS-TBNA also has high sensitivity for identifying non-caseating granulomas in hilar and mediastinal lymph nodes in cases of suspected sarcoidosis (Evidence level $2++$ ).

\section{THERAPEUTIC TECHNIQUES Debulking techniques}

There are a number of effective debulking techniques for the removal of endobronchial tumour; the treatment of choice will depend largely on cost and availability. Rigid bronchoscopy techniques have advantages in terms of airway control, the ability to easily remove a large volume of tumour, to dilate the airway and to deploy silicone stents. In the UK there are, however, relatively few experienced practitioners in rigid bronchoscopy outside surgical units. This guideline therefore covers the use of interventional techniques which utilise the more widely available flexible bronchoscopy.

In patients with intrinsic central airway obstruction, with or without critical airway narrowing, immediate debulking using endobronchial diathermy, argon plasma coagulation, cryoextraction and thermal laser may all be considered (Evidence level 3). Brachytherapy, conventional cryotherapy and photodynamic therapy (PDT) may also be considered for debulking if there is time for their delayed effect to take place. These techniques are not generally useful for extrinsic compression. Endobronchial diathermy, argon plasma coagulation and cryoextraction are all relatively safe, simple and are much cheaper than laser, brachytherapy and PDT. 
Table 1 Summary of the effectiveness of endobronchial debulking techniques

\begin{tabular}{|c|c|c|}
\hline & $\begin{array}{l}\text { Effectiveness in palliating } \\
\text { symptoms (\% patients) }\end{array}$ & $\begin{array}{l}\text { Effectiveness to open } \\
\text { airway ( } \% \text { patients) }\end{array}$ \\
\hline PDT & $100 \%^{1}$ & $80 \%^{2}$ \\
\hline Brachytherapy & $69-90 \%^{134}$ & $78-85 \%^{13} 4$ \\
\hline Cryotherapy & $70-93 \%^{15-7}$ & $77-79 \%^{15-7}$ \\
\hline Cryoextraction & $>90 \%^{8}$ & $83-91 \%^{8}$ \\
\hline \multirow[t]{2}{*}{ Laser } & $63-94 \%{ }^{9-11}$ & $>90 \%$ in trachea ${ }^{2}$ \\
\hline & & $\begin{array}{l}60-70 \% \text { for more } \\
\text { distal lesions }{ }^{2}{ }^{9-11}\end{array}$ \\
\hline Diathermy & $70-97 \%^{11-13}$ & $88 \%^{11-13}$ \\
\hline APC & $100 \%$ of haemoptysis ${ }^{14}$ & $91 \%^{114}$ \\
\hline
\end{tabular}

APC, argon plasma coagulation; PDT, photodynamic therapy.

These techniques are effective in alleviating symptoms of breathlessness and haemoptysis in patients with endobronchial malignancy (see table 1).

\section{Treatment of early lung cancer}

Many of these debulking techniques, including endobronchial diathermy, cryoextraction, brachytherapy and PDT, may also be used for the treatment of early central lung cancer with curative intent and for treating localised endobronchial disease in patients unfit for surgery or other radical therapy.

\section{Stents}

Following tumour debulking, self-expanding metal stents can effectively maintain airway patency and are also effective in the treatment of extrinsic compression (Evidence level 3). Nonremovable stents should be used with caution, if at all, in non-malignant disease due to the potential for stent fracture and other long-term complications.

\section{EMERGING APPLICATIONS FOR FLEXIBLE BRONCHOSCOPY}

There are a number of recent diagnostic and therapeutic applications using the flexible bronchoscope which have not yet established a clear place in routine practice. These include electromagnetic navigation bronchoscopy, treatment of emphysema by lung volume reduction using valves and bronchial thermoplasty for asthma.

\section{Electromagnetic navigation bronchoscopy}

The use of electromagnetic navigation bronchoscopy to locate tumour not visible under direct vision using three-dimensional data from a CT scan has been shown to yield a diagnostic rate of between $59 \%$ and $80 \%$, with greater accuracy for lesions $>40 \mathrm{~mm}$ in diameter. It is a safe, effective but currently expensive modality for sampling peripheral lesions, and studies using virtual bronchoscopy alone have similar diagnostic rates.

\section{Endobronchial valves}

Endobronchial valves may be used in the treatment of emphysema with severe hyperinflation, in an attempt to reduce lung volume. The valves are inserted into the target area via flexible bronchoscopy under conscious sedation or general anaesthesia. In patients with severe emphysema and hyperinflation they have been shown to produce small improvements in lung function (Evidence level 2-). Sufficient efficacy has not yet been demonstrated to recommend their routine use.

\section{Bronchial thermoplasty for asthma}

Airway smooth muscle may also have a role in the pathogenesis of asthma by secreting proinflammatory cytokines and promoting airway remodelling. The goal of bronchial thermoplasty is to reduce airway smooth muscle by the application of radiofrequency-generated heat at $65^{\circ} \mathrm{C}$. Although there is a high level of evidence for the effectiveness of this technique in reducing symptoms, adverse events and frequency of exacerbations (Evidence level 1), its place in the treatment of asthma remains to be established and we recommend that treatment should be limited to a few specialist centres in carefully selected patients.

\section{AUDIT, RESEARCH, TRAINING AND STANDARDS OF CARE}

The guideline provides audit, research and training recommendations, and also indicates recommended standards of care.

Competing interests None. A declaration of interest is available in Appendix 1 of the guideline.

Provenance and peer review Not commissioned; internal and external peer review undertaken by the Standards of Care Committee of the British Thoracic Society.

\section{REFERENCES}

1. Wahidi MM, Herth FJ, Ernst A. State of the art: interventional pulmonology. Chest 2007:131:261-74.

2. Beamis JF, Becker HD, Cavaliere S, et al. ERS/ATS statement on interventional pulmonology. European Respiratory Society/American Thoracic Society. Eur Respir J 2002;19:356-73.

3. Celebioglu B, Gurkan OU, Erdogan S, et al. High dose rate endobronchial brachytherapy effectively palliates symptoms due to inoperable lung cancer. Jpn $\mathrm{J}$ Clin Oncol 2002:32:443-8.

4. Lo TC, Girshovich L, Healey GA, et al. Low dose rate versus high dose rate intraluminal brachytherapy for malignant endobronchial tumors. Radiother Oncol 1995:35:193-7.

5. Walsh DA, Maiwand MO, Nath AR, et al. Bronchoscopic cryotherapy for advanced bronchial carcinoma. Thorax 1990;45:509-13.

6. Maiwand M0, Homasson JP. Cryotherapy for tracheobronchial disorders. Clin Chest Med 1995; 16:427-43.

7. Marasso A, Gallo E, Massaglia GM, et al. Cryosurgery in bronchoscopic treatment of tracheobronchial stenosis. Indications, limits, personal experience. Chest 1993;103:472-4.

8. Schumann C, Lepper PM, Barth TF, et al. Successful immediate cryorecanalization of a simultaneous high-grade tracheal and bronchial stenosis as rare manifestations of bronchial-associated lymphoid tissue lymphoma. J Thorac Cardiovasc Surg 2009:137:e17-19.

9. Cavaliere S, Foccoli P, Farina PL. Nd:YAG laser bronchoscopy. A five-year experience with 1,396 applications in 1,000 patients. Chest 1988:94:15-21.

10. Venuta F, Rendina EA, De Giacomo $\mathrm{T}$, et al. Nd:YAG laser resection of lung cancer invading the airway as a bridge to surgery and palliative treatment. Ann Thorac Surg 2002; 74:995-8.

11. Boxem T, Muller M, Venmans B, et al. Nd-YAG laser vs bronchoscopic electrocautery for palliation of symptomatic airway obstruction: a cost-effectiveness study. Chest 1999:116:1108-12.

12. Petrou M, Kaplan D, Goldstraw P. Bronchoscopic diathermy resection and stent insertion: a cost effective treatment for tracheobronchial obstruction. Thorax 1993:48:1156-9

13. Sutedja G, van Kralingen K, Schramel FM, et al. Fibreoptic bronchoscopic electrosurgery under local anaesthesia for rapid palliation in patients with central airway malignancies: a preliminary report. Thorax 1994;49:1243-6.

14. Crosta C, Spaggiari L, De Stefano A, et al. Endoscopic argon plasma coagulation for palliative treatment of malignant airway obstructions: early results in 47 cases. Lung Cancer 2001;33:75-80. 